\title{
Entrevista a Paulo Pinho
}

\section{Conduzida por Teresa Marat-Mendes ${ }^{1}$ e Patrícia Bento d'Almeida ${ }^{2}$, a 30 de outubro de 2020}

Paulo Pinho (Porto, 1956) é Professor Catedrático de Planeamento do Território e Ambiente na Faculdade de Engenharia da Universidade do Porto desde 1999. Fundador e Diretor do CITTA - Centro de Investigação do Território, Transportes e Ambiente (FCT - UP/UC).

Secretário Geral da Associação Europeia das Escolas de Planeamento Urbano, entre 2015 e 2019. Licenciado em Enga Civil em 1978 (FEUP), Pós-graduação (Curso de Mestrado) em Planeamento Regional e Urbano pela Universidade de Strathclyde em 1982, e Doutoramento em Planeamento Regional e Urbano na Universidade de Strathclyde, Glasgow, em 1985. Prestou provas de Agregação na FEUP em 1997.

É autor (ou co-autor) de mais de 150 publicações. Foi Membro do Conselho Superior de Obras Públicas, Consultor da Comissão Europeia (DGXI), Consultor do Ministério do Ambiente e Ordenamento do Território, Assessor da Comissão de Coordenação da Região do Norte e Consultor da Comissão de Coordenação da Região Centro.
Teresa Marat-Mendes é Professora de Projecto Urbano e Urbanismo Ecológico no Departamento de Arquitectura e Urbanismo do ISCTE-IUL. Doutora pela Universidade de Nottingham com a tese 'The sustainable urban form'. A sua principal linha de investigação é o estudo da forma urbana, do metabolismo e da sustentabilidade. Actualmente, coordena no DINÂMIA'CET-Iscte a investigação transdisciplinar do Projecto SPLACH Spatial Planning for Change.

Patrícia Bento d'Almeida é Arquiteta e Investigadora Integrada no DINÂMIA'CET-Iscte. Com Mestrado (2007) e Doutoramento em História da Arte Contemporânea (2013) pela Faculdade de Ciências Sociais e Humanas da Universidade Nova de Lisboa, os principais temas de investigação centram-se em temáticas da História da Arquitectura e do Urbanismo Contemporâneo.

Foi coordenador principal de vários projetos de investigação em Portugal e no estrangeiro, no âmbito da Sustentabilidade Urbana. Como avalia a evolução desta temática na prática e na teoria do Planeamento Urbano?

Isto é uma grande questão e dá "pano para mangas" ... em primeiro lugar, em termos genéricos, a evolução é positiva. Vou-me reportar aos anos que tenho memória - e acabam por ser já alguns. Se olhar para trás, para os últimos quarenta anos, vejo uma diferença muito significativa na prática do planeamento, no modo como as questões ambientais são discutidas em Portugal e, naturalmente, no modo como as ideias que muitas vezes têm origem no estrangeiro e depois acabam por nos influenciar. Se me posso recordar, eu diria que, no início dos anos 80 - estava eu a começar o meu doutoramento sobre políticas de ambiente e o papel do planeamento do território -, estávamos nós claramente ainda naquilo que eu uma vez designei como a primeira geração das políticas de ambiente. A palavra-chave então, quando se tratava de políticas

\footnotetext{
${ }^{1}$ teresa.marat-mendes@iscte-iul.pt

2 patricia.bento.almeida@iscte-iul.pt.

Copyright (C) 2021 (Marat-Mendes, T., Almeida, P.B.) 
ambientais, era 'conservação da natureza'. Era o mundo dos biólogos. O Parque Nacional da Peneda Gerês tinha sido lançado e já estava concretizado no terreno - ainda nos anos 70 -, portanto era uma visão ainda muito na via defensiva da política de ambiente. Muito reativa, era qualquer coisa que interessava a meia dúzia de pessoas, que viam algumas espécies ameaçadas, alguns habitats em perigo e, portanto, era preciso protegê-los. A proteção segundo a lógica na altura era de pura e simplesmente afastar a intervenção humana, e com isso resolviam-se os problemas. Lembro-me que, ainda no final dos anos 70, ocorriam conflitos de natureza social, entre o Estado e as autarquias, por exemplo no Parque Nacional da Peneda Gerês, porque, pela primeira vez, com a criação do parque, aplicaram-se uma série de medidas que impediam as normais práticas de exploração daquele território, a que as pessoas estavam habituadas, e que as autarquias também davam voz. Portanto, ainda num período de ditadura, antes de 74, geraram-se conflitos motivados pela criação de um parque nacional. A primeira geração das políticas de ambiente em Portugal acabou por, neste caso concreto, ter consequências significativas. Depois, aí nos anos 80 - isto é um assunto que algumas vezes abordo em aulas minhas, devo dizer -, há uma evolução, quer no debate internacional, quer no debate nacional, em que deixamos, por momentos, a conservação da natureza e passamos ao controlo da poluição. A poluição, da água, do ar e, mais tarde, do solo, passa a ser a palavra-chave das políticas ambientais, isto nos anos 80 em Portugal, com aliás uma certa décalage em relação ao debate Europeu de cerca de uns vinte anos, e em relação aos Estado Unidos de cerca de trinta anos. Depois, nos anos 90, aparece o conceito de 'desenvolvimento sustentável'. Demora um tempo a chegar a Portugal, nós ainda continuamos durante os anos 90 e início deste século com o termo 'ambiente' para designar os recursos naturais, as questões da poluição, a conservação da natureza e, portanto, passados uns 10 ou 15 anos é que a questão da sustentabilidade começa a entrar no nosso debate, e começa a ter consequências em termos de práticas de planeamento. Atualmente, o grande debate são as questões das alterações climáticas. Entramos na quarta geração das políticas ambientais. $\mathrm{Na}$ área do planeamento ainda temos muito que fazer para perceber até que ponto o planeamento, e a prática do planeamento, pode responder aos desafios das alterações climáticas. Temos ideia de que, ao nível da adaptação, há aqui um papel importante a desempenhar, ao nível da mitigação esse papel ainda não é tão claro mas, em suma, quando eu olho para trás vejo uma evolução clara e vejo uma outra coisa curiosa que é a décalage temporal no debate geral das ideias entre aquilo que é a esfera internacional e a esfera nacional, ter vindo a reduzir-se ao longo do tempo. Obviamente que estamos numa outra época, estamos numa época em que as ideias passam muito mais rapidamente, há meios muito mais eficazes de fazer passar essas ideias, mas, para além da questão da evolução e da rapidez com que as ideias neste momento passam, há a questão das práticas. Ainda há dias num outro contexto, defendia que há uma comunidade de práticas a nível Europeu que claramente acaba por percolar para o contexto nacional, e muitos de nós sentimo-nos membros dessa comunidade de práticas europeias nestas questões do planeamento, do ambiente, da sustentabilidade, e portanto acabamos por, mais rapidamente, neste momento, reagir do que reagíamos no passado. Ao nível do debate de ideias, isto é aquilo que eu poderia dizer em relação à questão colocada, ou seja como as políticas foram evoluindo. No âmbito da prática aí convenhamos que aquilo que era um debate teórico interessante e emergente nos anos 80, e que continua a ser muito válido em Portugal, está longe de se ter concretizado na prática. Lembro-me que, nos anos 80 , quando estava a fazer a minha tese de doutoramento, ter lido alguns artigos sobre aquilo que na altura alguns autores chamavam de o "gap de implementação", que era a ideia de que, na área do ambiente, ao contrário de outras áreas sectoriais, havia um gap muito maior entre aquilo que eram os desejos e os objetivos que estavam nas políticas e aquilo que depois se concretizava no terreno. Daí o termo "gap de implementação" aplicado especificamente às políticas de ambiente. Lembro-me perfeitamente de ter feito uma referência na minha tese de doutoramento a esta ideia. Olhando para a situação atual, eu ainda verifico um gap enorme entre aquilo que é o discurso teórico e político sobre estas questões e aquilo que é a efetiva prática no terreno. Há umas boas exceções em Portugal, é um facto, há uns municípios mais bem apetrechados tecnicamente, com uma visão mais ambiciosa do ponto de vista político, também com mais meios, em que conseguimos ver coisas a correr de uma forma interessante e muito em linha com aquilo que são as práticas noutros países europeus. Eu falo sobretudo do caso europeu porque, para mim, se trata de um contexto mais interessante que outros casos noutras partes do mundo. Mas quando olho para os 300 municípios em Portugal, tenho de concluir que os tais municípios que eu estava a referir ainda são uma minoria. Ainda há dias, no âmbito do projeto SPLACH, fizemos um levantamento da situação dos PDMs a nível nacional. Tinha ideia que a situação não era brilhante, mas nunca pensei que fosse o que efetivamente 
é. Temos ainda uma percentagem muito significativa de municípios que funcionam com PDMs de primeira geração, portanto, dos anos 90. Naturalmente que todo este debate que ocorreu posteriormente não pode estar incorporado nesses PDMs. Eu diria até que, de um ponto de vista politico, nestas matérias do ambiente, o nosso discurso a nível nacional e europeu foi sempre um discurso conotado com o dos países mais ambiciosos nesta matéria, e isto desde a atualidade - veja-se por exemplo o que se passa na incorporação de energias renováveis na produção de eletricidade que é de facto bastante significativo - até quase à génese das políticas ambientais, como nos tempos do Ministro Gonçalo Ribeiro Teles e depois com o Secretário de Estado do Ambiente Carlos Pimenta que, sobretudo a nível europeu, tinha um discurso claramente alinhado com os países mais avançados nesta área. Portanto, ao nível do discurso e da conceção teórica eu diria que estamos bem, mas ao nível da prática, aí manifestamente ainda há muita coisa por fazer.

Aquela referência da intervenção que eu fiz à Peneda Gerês, não foi uma intervenção da elite nacional, foi uma questão muito local e muito sentida. Foi vista como uma intromissão do Estado Ditatorial num território, em nome de uma conservação da natureza que ninguém percebia, porque quem fazia a natureza eram as pessoas que lá estavam, era quem agricultava a terra, quem pastoreava, etc. Mas houve efetivamente um conflito significativo entre alguns municípios, mesmo com a pouca margem de manobra que eles tinham na altura, e as comunidades locais, com a implantação do Parque Nacional da Peneda Gerês. Aqui está uma dimensão social das políticas ambientais que nunca vi tratada com profundidade.

Outra coisa interessante foi a proposta de uma central nuclear em Ferrel, junto ao mar, aproveitando a água do mar para a refrigeração da central. Nessa altura o país podia ter virado nuclear. A França já era, a Espanha também. Isto no final dos anos 70. Esta proposta mobilizou muita gente, sobretudo do país mais politizado e contribuiu para a emergência ou consolidação de vários grupos ecologistas - já havia alguns na altura -, embora muitos deles perfeitamente inorgânicos. Foi um momento curioso. Com esse debate e essas manifestações conseguimos arrumar a opção nuclear de vez. Num país com pouca energia, como é o nosso, a opção nuclear era extremamente atrativa, até porque os nossos principais parceiros tinham enveredado pela opção nuclear. Isto teve um significado importante. É um período de manifestação publica, de abaixoassinados, de uma certa mobilização da sociedade. Obviamente que era uma certa elite que participava, convenhamos, mas era interessante porque ela provinha de vários quadrantes, quer em termos ideológicos, quer em termos sociais e geográficos. Como disse, foi um momento curioso que a maior parte das pessoas já nem se lembra. Praticamente erradicou do debate nacional toda a questão da energia nuclear que, era teoricamente, muito apetecida.

Figura 1. Manifestação do povo contra a central nuclear, Ferrel, 1978

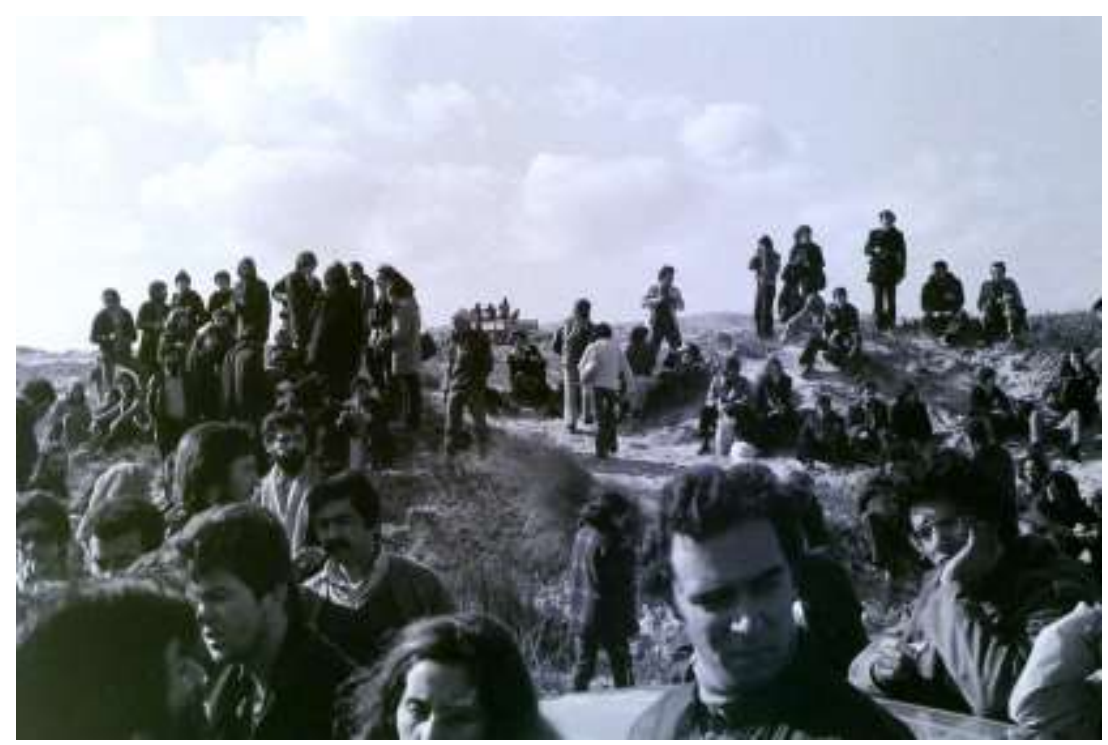

Fonte: Ephemera, Biblioteca e Arquivo de José Pacheco Pereira. Fotografia de José António Miranda. 
Figura 2. Debate 'Pela vida contra o Nuclear', Ferrel, 1978

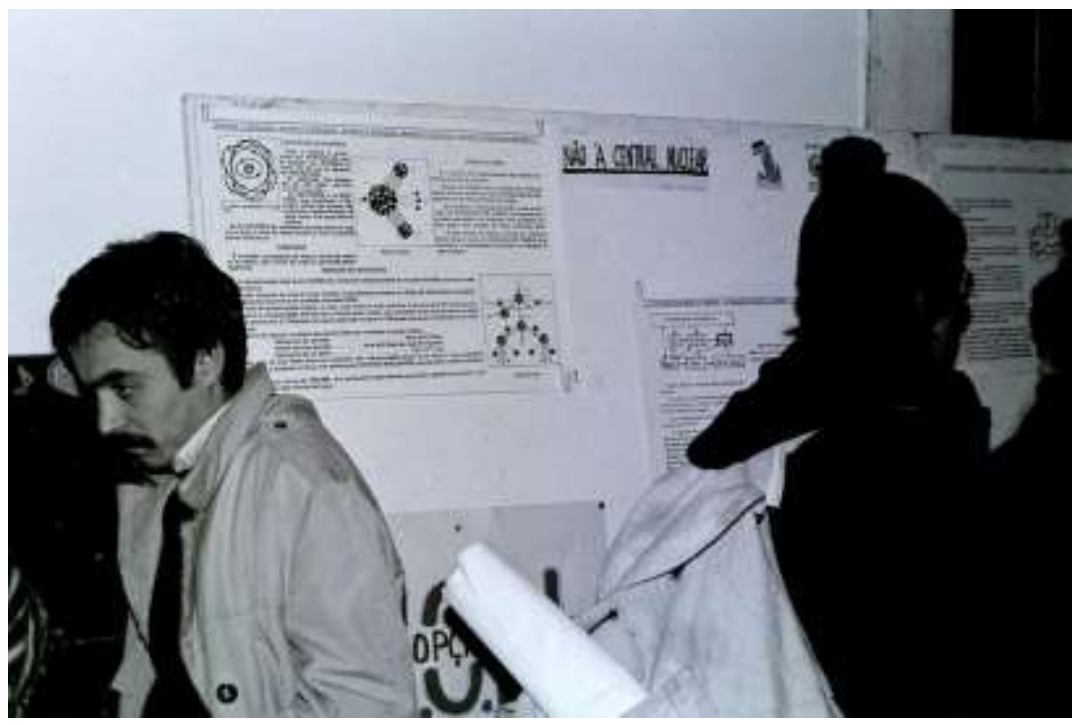

Fonte: Ephemera, Biblioteca e Arquivo de José Pacheco Pereira. Fotografia de José António Miranda.

O Projeto SPLACH tem como objetivo principal preparar um compendio de boas párticas, para uma transição sustentável do atual planeamento Urbano. Porque considera este um assunto urgente e necessário?

Ao longo destes últimos anos - olhando estritamente para o nosso sistema de planeamento -, não conseguimos identificar lacunas graves ao nível da sua concepção, isto é, temos um quadro legal e regulamentar que é, eu diria, suficientemente estável e maduro. Aliás até é interessante verificar que na última década tem havido alterações na cor política dos governos e o quadro tem-se mantido com razoável estabilidade, o que é um sinal de maturidade. Só que isso não basta para melhorarmos a prática profissional. No fundo, o que o nosso quadro legal e regulamentar faz é dizer-nos o que é que nós não podemos fazer. O quadro legal e regulamentar não nos dá pistas concretas sobre aquilo que nós devemos fazer. Esta dimensão doutrinária está ainda ausente em Portugal. Não digo que não haja no passado, e até mais recentemente, alguns trabalhos que procuraram cobrir lacunas parcelares em alguns temas cobertos pela ampla área de intervenção do planeamento, mas eu não encontro uma produção sistemática de documentos de orientação das práticas que permita ir para além daquilo que é o atual quadro legal e regulamentar e contentamo-nos em discutir apenas o que se pode e não pode fazer, ou seja, o que é legal ou não é legal. Para avançarmos temos claramente que enveredar pela produção de documentos doutrinários, que têm de ser suficientemente flexíveis para poder abarcar as diversas realidades deste nosso país, portanto eles não devem ser demasiado impositivos e devem ser documentos que suscitem uma discussão, e que permitam perceber aquilo que são as melhores, ou menos boas, práticas de planeamento. O SPLACH é um projeto que tem exatamente esta preocupação. A ideia fundamental que presidiu à conceção do projeto foi reconhecer que temos um quadro legal e regulamentar maduro e razoavelmente completo, mas que ainda nos falta muito em termos de desenvolvimento doutrinário. Portanto, é neste aspeto da produção de orientações para a prática do planeamento que nós estamos agora focados nesta fase final do projeto.

A investigação científica conduzida no âmbito do planeamento urbano é cada vez mais diversificada e abrangente. Contudo o planeamento urbano em Portugal encontra-se ainda muito fixado em 'velhas' escolas e metodologias. Que razões identifica para uma certa inércia na mudança e evolução do próprio planeamento? Atores, Instrumentos?

Acho que é uma excelente questão e vem, na verdade, ajudar a perceber a situação em que nos encontramos neste momento. Quando eu dizia que tínhamos um quadro legal e regulamentar suficientemente maduro, 
ele efetivamente é, mas a atitude geral de quem pratica o planeamento é de cumprir os mínimos. É preciso fazer planos e, sim, fazem-se! O país está coberto de PDMs. Mas depois não nos preocupamos com o seu prazo de validade, que é de 10 anos. Ao fim do sexto ou sétimo ano, já devíamos estar a pensar na sua revisão que era para entrar depois, e a tempo, o novo plano revisto. Dito isto, e para agravar, o nosso sistema é ainda muito "plano-dependente" e, muito em particular em relação ao Plano Diretor Municipal. Nós de facto temos planos, mas eu diria que o que temos em planos a mais, temos em planeamento a menos, isto é, cultivamos uma posição muito reativa perante o processo de planeamento. As autarquias normalmente não têm uma ideia muito clara e concreta sobre o seu território - pese embora algumas honrosas exceções - e, portanto, basicamente esperam que as iniciativas privadas ou públicas apareçam e depois acomodam essas iniciativas nos instrumentos de planeamento em vigor. Portanto isto é uma posição muito reativa. Ora, para termos verdadeiramente planeamento, temos de ter uma posição proativa e seria esta posição proativa que nos levaria a evoluir em termos de ferramentas. Aquilo que é referido na pergunta das "velhas escolas" e metodologias, tem muito a ver com esta postura reativa do planeamento em Portugal e não proativa. A este nível temos que evoluir rapidamente, há muito a fazer nesta área e há, sobretudo, uma nova atitude, uma nova postura perante o que é planeamento, isto é, o planeamento não se esgota quando se faz um plano, ou quando se faz a revisão de um plano. A aprovação de um plano não deve ser vista como um fim, mas deve ser vista meramente como o início de um processo de planeamento. O território tem que estar sistematicamente a ser pensado por quem tem responsabilidades para o gerir, ele tem que estar sempre na mente dos decisores e técnicos de planeamento que estão nos nossos municípios, e não fazermos o plano como documento de consulta. Aparece um pedido de licenciamento e depois vai-se ver se está ou não está de acordo com o que diz o plano, e se não está de acordo propõem-se três ou quatro alterações, e é tudo. É uma posição passiva que em nada encoraja a adoção de posturas mais ambiciosas, em que estas questões das alterações climáticas, da economia circular, da descarbonização das cidades, entrem de corpo inteiro. Acho que há aqui responsabilidades repartidas, quer em relação aos atores, quer em relação aos instrumentos, quer em relação aos processos de planeamento adotados. Esta é uma área em que nós ainda temos muito que fazer, não é necessário fazer uma reformulação completa do sistema legal e regulamentar, não é essa a grande questão, a questão é sobretudo como é que levamos este sistema a uma prática proactiva, antecipando e orientando os processos de desenvolvimento, aí é que de facto temos muito a fazer.

\section{Relativamente ao facto de termos muito a fazer, pensa que isso é possível com os atores que temos de momento?}

Eu tenho a sensação que temos de partir com os recursos humanos que existem neste momento. Não podemos ignorar a situação de partida, mas temos de introduzir maior ambição e maiores níveis de exigência e elas têm que partir dos níveis superiores, seja ao nível regional, no papel das Comissões de Coordenação Regional, seja ao nível nacional, no papel da Direção Geral do Território, ou do próprio Ministério da tutela, no sentido de criarem mecanismos e incentivos que tornem a pratica do planeamento urbano mais exigente e qualificada. Tenho a sensação que é uma ilusão imaginarmos que os atores que estão no terreno podem pura e simplesmente ser substituídos, ou ser ignorados, porque são eles que, bem ou mal, conduzem "as coisas" e portanto a questão não é tanto a sua substituição mas é, sobretudo, a criação de mecanismos e incentivos para melhorarem a sua prática profissional. Muitas vezes, exatamente por falta desses mecanismos, o incentivo acaba por ser pouco interessante, e entramos assim num círculo vicioso em que a tal dimensão proativa do planeamento é sempre sistematicamente ignorada.

\section{Qual a importância da interdisciplinaridade para uma transição sustentável? Como poderá esta ser efetivada?}

Eu acho que há duas dimensões complementares que são a dimensão interdisciplinar da ação do planeamento no território, isto é, aquilo que se passa entre disciplinas, entre áreas disciplinares, e as pontes que se podem estabelecer entre elas; mas existe também uma outra dimensão, que não é menos importante que a interdisciplinaridade, que é a pluridisciplinaridade, isto é, os olhares cruzados sobre uma mesma realidade, neste caso, a cidade. Nós ganhamos imenso com estas visões cruzadas, provindas de várias disciplinas, mas também ganhamos com a dimensão interdisciplinar, das pontes que se vão estabelecendo entre engenheiros, arquitetos, sociólogos, economistas, antropólogos, e que enriquecem o olhar sobre a 
cidade. Sabemos que as grandes questões urbanas, atualmente, não são tanto de natureza física - o hardware da cidade - como aconteceu no passado, mas tem muito mais a ver com um software instalado na cidade, as suas funções e transformações económicas e sociais. A uma produção excessiva de edificado no passado contrapõe-se a contração populacional que temos assistido mais recentemente, e o facto de muitas atividades económicas serem cada vez menos consumidoras de espaço. Daí encontrarmos, em muitos territórios, excesso de edificado para aquilo que é efetivamente necessário. Claro que muitas vezes há edificado que não se adapta às condições para que está a ser utilizado, mas isso é um outro problema. Mas, neste momento, para intervir na cidade, é muito mais pela perceção do software - e aqui vou introduzir a dimensão dos modos de vida, dos estilos de vida - do que propriamente pela reorganização física ou infraestrutural das nossas cidades. Não digo que isso não continue a ter uma dimensão importante, porque tem, mas dificilmente conseguimos pensar numa cidade, por exemplo pós-carbono, se não introduzirmos a dimensão dos modos de vida e dos estilos de vida. Curiosamente, os tempos atuais da pandemia vieram explicitar a importância destas dimensões. Vieram revelar como a hipermobilidade, por exemplo, que está muito ligada a alguns modos e estilos de vida, é de um ponto de vista ambiental um completo desastre. Portanto, temos de encontrar formas de interagir, valorizar o local, a unidade de vizinhança e a proximidade, porque é aí que encontramos soluções mais sustentáveis. E isso passa-se quer no domínio das deslocações, quer no domínio do sistema agroalimentar, enfim, passa-se numa série de sistemas sociotécnicos que convergem e que explicam o modo de funcionamento das nossas cidades na atualidade. E daí, para fechar a resposta, a importância das dimensões interdisciplinar e pluridisciplinar - dimensões diferentes e complementares -, mas essenciais para percebermos a nova realidade que é a cidade de hoje. Na sua opinião, como é que a ciência pode auxiliar as instituições políticas a desenvolver um
planeamento territorial mais sustentável?

A ciência tem neste campo um grande papel que é o de fornecer aquilo que chamamos evidência científica. A evidência científica permite desmontar os problemas e permite encontrar as melhores soluções. No entanto, isto a que chamo evidência científica, é qualquer coisa que tem de ser contextualizada e partilhada, isto é, não basta saber muito, ter muito conhecimento teórico, para se ser necessariamente um bom profissional do planeamento. É preciso ter de facto um background sólido, estar ao corrente do debate de ideias atual, mas ser capaz de ouvir e contextualizar esse debate porque se há coisa que aprendemos no planeamento é que cada caso é um caso, a cidade é de todos e o planeamento um exercício de partilha. A importação de uma boa ideia sem o cuidado da sua adaptação e assimilação pode ser um perfeito desastre. Eu diria que a ciência tem um papel fundamental nesta área, como em qualquer outra área de cariz profissional. Curiosamente, é em tempos de crise que se apela à intervenção da ciência, quando está tudo bem ninguém liga à ciência, mas quando estamos em crise (refiro-me à atual pandemia) e os próprios políticos não sabem o que devem fazer, então aí, vamos cá “ouvir os sábios”. Só que, convenhamos, estes "sábios", têm de ter os pés bem assentes na terra e uma particular sensibilidade social. Portanto, eles devem saber processar o tal saber científico, a tal evidência científica, mas devem perceber muito bem o contexto em que as decisões são tomadas, saber ouvir e interpretar os anseios das comunidades locais e só a partir daí é que se pode mobilizar a utilidade da ciência para desenhar melhores soluções técnicas. É a evidência contextualizada que é para mim uma das chaves do sucesso da ciência enquanto motor da transformação. 